\begin{tabular}{|c|c|c|c|c|c|}
\hline * & $\alpha$ & 1903.0 & $\delta_{\mathrm{I}}$ & 03.0 & Autorität \\
\hline 19 & $18^{h}$ & $41^{m} 5^{8 s} \cdot 29$ & $+61^{\circ}$ & $55^{\prime} \quad 8.4$ & $\begin{array}{l}\text { 3D., Anschl. } \\
\text { ( } 9 \circ 3.67)\end{array}$ \\
\hline 20 & 18 & 4321.17 & $+6 I$ & $5 \circ 30.2$ & AG. Hels. \\
\hline 21 & 17 & 5937.25 & +65 & 1050.1 & $\left\{\begin{array}{l}10.3 \text {, Anschl. an } * 22 \text { (Ep. } \\
1903.66)\end{array}\right.$ \\
\hline 22 & 18 & $5 \quad 13.90$ & +65 & 53.6 & $\left\{\begin{array}{l}1 / 2(\text { AG. Hels. } 9646+\text { AG. } \\
\text { Christ. 2790) }\end{array}\right.$ \\
\hline 23 & & 1350.74 & +68 & $3^{8} \quad 30.9$ & $\left\{\begin{array}{l}9{ }^{\mathrm{m}} \cdot 7, \text { Anschl an } * 24 \text { (Ep. } \\
1903.57)\end{array}\right.$ \\
\hline
\end{tabular}

Bemerkungen.

Von Juli $I 1$ an erfolgten die Beobachtungen bei heller roter Feldbeleuchtung; ihre Ausdehnung über Aug. 7 hinaus hat leider die anhaltend schlechte Witterung vereitelt.

Die äußere Erscheinung des Kometen verlief in ähnlicher Weise, wie die des fast gleich hellen Perrineschen Kometen 1902 III. In den ersten Tagen nach der Entdeckung gingen keine neanenswerten Veränderungen in dem Gebilde vor sich. Als es am 22. Juni zum erstennal gesehen wurde, betrug die größte Länge (bei 154 -facher Vergrößerung) 4:5, der Durchmesser der Koma 2' und der sehr verwaschene Schweif schoß im PW. $220^{\circ} \pm$ aus. Im Sucher des großen Refraktors $(12.2 \mathrm{~cm}$ Öfnung und $3 \mathrm{I}$-fache Vergrölerung) erstreckte sich der Komet allerdings uber I $5^{\prime}$. Bei starken Vergrößerungen, 407 und 725 , erkannte man deutlich, daß die innerste Partie des Kopfes aus einem scharfen fixsternartigen Kern bestand, den eine Zone grober Körner umlagerte, eine Wahrnehmung, die wăhrend der ganzen Dauer der Sichtbarkeit auffiel. Der Durchmesser des eigentlichen Kernes wurde an zwei Tagen (Juli I I und 15) libereinstimmend $2 u$ o:8 gefunden. Nachdem der Komet am 26. Juni dem bloßen Auge erkennbar geworden, hatte der Schweif am 2. Juli, im Sucher des groben Refraktors betrachtet, eine Länge von $20^{\prime}$ erreicht und stieg nun rasch

Straßburg i. F., 1903 Sept. 5.

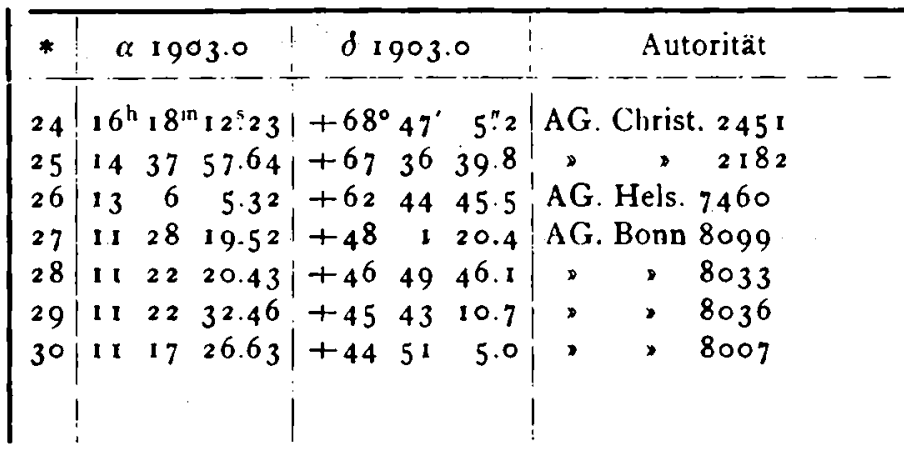

an: Juli I 3 war er $45^{\circ}$ lang im PW. $185^{\circ}$, Juli 14 schon $65^{\circ}$ bei $10^{\circ}$ Breite; Juli 18 ist die Koma $30^{\prime}$ breit, der Schweif $x^{\circ} 5$ lang und Juli 25 konnte gar in einem lichthellen Hand. fernrohr (8.3 cm Öffuung und 7.8-fache Vergrößerung) der Schweif uber $5: 5$ verfolgt werden. Er erschien stets gerade, gegen das Ende konisch spitz zulaufend.

Mit I I -facher Vergrößerung erhielt ich die folgenden, bei der zerflossenen Begrenzung aller Partien des Objektes nicht sehr genauen PW.-Einstellungen des Schweifes:

\begin{tabular}{rr|crr} 
Juni 27 & $224^{\circ} .1$ & Juli & 2 & $210 \% 1$ \\
28 & 227.3 & . & 14 & 177.8 \\
Juli 1 & 206.5 & Aug. & 5 & 56.6
\end{tabular}

Schwingungen der Schweifachse um eine Mittellage sind hier vielleicht angedeutet.

Über die in Straßburg angestellten Helligkeitsschätzungen und -Messungen des Kometen wird eine besondere Mitteilung berichten.

Juni 29. Deklinationseinstellung unsicher. - Juli 17 , 18. Identifikation der Vergleichsterne nicht völlig gesichert. - Aug. 6. Störung durch Wolken; Dekl, wegen Versagens des Typendruckapparates verloren.

C. W. Wirtz.

\title{
Osservazioni della cometa 1903 IV (1903 c)
}

con l'equatoriale di Merz di $26 \mathrm{~cm}$, fatte nel R. Osservatorio di Palermo.

\begin{tabular}{|c|c|c|c|c|c|c|c|c|c|}
\hline $19 \circ 3$ & T. m. Pal. & $\Delta \alpha$ & $\Delta \delta$ & Cf. & $\alpha$ ap & $\log p .4$ & $\delta$ app. & $\log p \cdot \Delta$ & Red. ad 1. app. \\
\hline & $15^{\mathrm{h}} 20^{\mathrm{m}} 6^{\mathrm{s}}$ & $-1^{m} 10^{5} .54$ & $-12^{\prime} 33^{\prime \prime} \cdot 5$ & 9.9 & $21^{\mathrm{h}} 50^{\mathrm{m}} \quad 8^{\mathrm{s}} \cdot 39$ & 8.6136 & $-5^{\circ} 25^{\prime} 17^{\prime \prime} .1$ & $4 n$ & $+2 s_{45}+16.4$ \\
\hline 25 & 1408 & +125.95 & $-\circ 35.9$ & $5 \cdot 5$ & $\begin{array}{lll}21 & 49 & 10.66\end{array}$ & 9.2791 & $\begin{array}{lll}-4 & 27 & 17.6\end{array}$ & $62 I_{n}$ & $+2.50+16.3$ \\
\hline 25 & 1438 & +124.14 & +051.3 & 6.6 & $\begin{array}{lll}21 & 49 & 8.85\end{array}$ & 9.0746 & $\begin{array}{lll}-4 & 25 & 50.4\end{array}$ & $0.764 \mathrm{In}$ & $+2.50+16.3$ \\
\hline 26 & $13 \quad 48 \quad 24$ & -136.17 & +521.3 & 5.5 & $\begin{array}{lll}21 & 48 & 0.32\end{array}$ & 9.2932 & $\begin{array}{lll}-3 & 21 & 46.9\end{array}$ & $0.7534 \mathrm{n}$ & $+2.52+16.2$ \\
\hline 26 & 141030 & $-137.5^{8}$ & +621.2 & 6.6 & $2147 \quad 58.91$ & 9.1922 & -32047.0 & $0.7544 n$ & $+2.52+16.2$ \\
\hline
\end{tabular}

Micrometro ad anelli.

Posizioni medie delle stelle di confronto.

$$
\begin{aligned}
& \text { * a } 1903.0 \quad \delta 1903.0 \quad \text { Autorità } \\
& \text { I } \quad 21^{\mathrm{h}} 51^{\mathrm{m}} 16^{\mathrm{s}} .48-5^{\circ} 13^{\circ} \quad 0^{\mathrm{m}} .0 \quad W_{1} 1139 \\
& 2 \quad 214742.21 \quad-426 \quad 58.0 \quad \text { Baily } 42638 \\
& \begin{array}{lllllllll}
3 & 2 \mathrm{~J} & 49 & 33.97 & -3 & 27 & 24.4 & W_{1} & 1103
\end{array}
\end{aligned}
$$

Palermo, 1903 Agosto 15. 